\title{
TEATRALIDAD Y ESCENOGRAFÍA DEL RECURSO DEL TRAVESTISMO EN EL TEATRO DE CALDERÓN DE LA BARCA
}

\section{Rosa Ana Escalonilla López}

Como es bien sabido, el travestismo ${ }^{1}$ constituye uno de los recursos omnipresentes en el teatro aurisecular. Desde Lope de Vega a Moreto, pasando por Tirso de Molina, Mira de Amescua, Rojas Zorrilla o Sor Juana Inés de la Cruz, hallamos abundantes testimonios de la enorme utilización de este recurso en la escena dramática del Siglo de $\mathrm{Oro}^{2}$. Calderón lo emplea tanto en comedias y piezas breves como en autos sacramentales ${ }^{3}$. A través de la observación de su dramaturgia se constata la existencia de una rica variedad de tipos de

1 Según el DRAE, travestir es 'vestir a una persona con la ropa del sexo contrario'.

2 Los títulos dramáticos del Siglo de Oro en que aparecen mujeres vestidas de hombre fueron recogidos por Carmen Bravo-Villasante (1976). Aunque la lista no se halla completa, sí sirve este estudio pionero como reflejo del extenso empleo que los dramaturgos del Siglo de Oro dieron a este recurso. En un estudio más breve, Jean Canavaggio (1979) recoge algunas de las obras en que aparece el recurso inverso, es decir, el del hombre disfrazado de mujer, en la comedia.

3 Véase al final de este artículo la relación de obras en que aparece el recurso del travestismo. 
disfraces ${ }^{4}$, coincidentes todos ellos en emplear artificios destinados a desfigurar al personaje con el fin de que no sea conocido, pero diversos en los mecanismos escénicos empleados para lograr esa desfiguración. Dentro de éstos hay múltiples posibilidades: desde el cambio o intercambio de trajes y la utilización de mantos, rebozos, velos o máscaras hasta los juegos de ocultamiento en la oscuridad, pasando por las variaciones de actitud o de voz, los silencios, la inadecuada recepción de la identidad ficticia por otros personajes, los mecanismos tramoyísticos a modo de escondites, el lenguaje, la mímica, etc. Así, por ejemplo, encontramos obras en que el elemento escénico utilizado para disfrazar al personaje es la oscuridad, como el drama ${ }^{5}$ Ni amor se libra de amor, en que Cupido aparece en todo momento, frente a Siquis, en escenas caracterizadas, desde el punto de vista escénico, por la oscuridad, pues si su amada le descubre, la diosa Venus, madre del dios del Amor, desatará su ira sobre ellos. En el auto ${ }^{6}$ Psiquis y Cupido (para Toledo y para Madrid), los mecanismos empleados son la oscuridad y el velo que cubre el rostro de Cupido. También en las comedias ${ }^{7}$ La dama duende y El galán fantasma se utiliza el recurso de la oscuridad para ocultar identidades, aunque de forma paralela a otros mecanismos escénicos como la alacena y la mina. En El encanto sin encanto Serafina despliega su ingenio para conquistar a Enrique. Los recursos empleados para disfrazar a los distintos personajes según las necesidades de la acción son: las máscaras, las tapadas, el cambio de personalidad a través de la adopción de una indumentaria ajena al personaje, el empleo de un idioma distinto del habitual en el disfrazado, los silencios, la mímica y el intercambio de vestimentas. Otras obras en las que también se usa el disfraz de personalidad son, por ejemplo, las piezas breves ${ }^{8}$ Las Carnestolendas (entremés), Los sitios de recreación del rey, La garapiña y Los guisados (mojigangas).

Dentro de la extensa variedad a la que acabamos de hacer referencia, se inserta el tipo de disfraz que lleva consigo el rasgo del travestismo,

4 Según la definición del Diccionario de Autoridades, disfraz es un «artificio para disimular o encubrir alguna persona o cosa, que no sea conocida, desfigurándola».

5 En lo sucesivo citaremos, para los dramas, por Valbuena Briones (1991, t. II). Consignaremos tomo, jornada y página.

6 Para los autos, seguimos la edición de Valbuena Prat $(1991$, t. III), mediante el registro del tomo y la página.

7 Para las comedias, utilizamos los textos de Valbuena Briones $(1987$, t. I). Consignaremos tomo, jornada y página.

8 Para las piezas breves, citaremos por Evangelina Rodríguez y Antonio Tordera (1982). Consignaremos página y versos. 
que, aunque básicamente consiste en la utilización de la indumentaria propia del otro sexo, en la práctica histriónica barroca lleva consigo también la adopción de muchos otros signos escénicos que suponen igualmente elementos de transgresión. El porqué de su utilización masiva dentro del teatro, no sólo calderoniano sino de todo el Siglo de Oro, se encuentra en relación directa con el espectacular éxito que tuvo entre el público de aquella sociedad, como ya lo afirmaba Lope de Vega en su Arte Nuevo de hacer comedias ${ }^{9}$.

Pero, como sabemos por distintos testimonios de la época ${ }^{10}$, el recurso del travestismo fue objeto de continuas polémicas y diatribas morales, que no lograron, sin embargo, reducir su empleo en las representaciones dramáticas de la época. Su presencia en las tablas aumentaba la teatralidad y espectacularidad de la escena tanto por la morbosidad que provocaba como por los elementos escénicos que llevaba consigo su utilización, y ello redundaba en los abundantes beneficios económicos de hospitales y representantes. Al público le entusiasmaba y acudía gozoso a las representaciones. Por su parte, la nobleza, con el rey Felipe IV a la cabeza, se deleitaba también del ambiente histriónico y carnavalesco, participando activamente en tales espectáculos ${ }^{11}$.

El disfraz funcionaba como elemento de ficción dentro de la propia ficción que ya constituía de por sí la pieza teatral. La introducción de un plano ficticio dentro de la comedia otorgaba a ésta, frente al espec-

9 vv. 280-283. Véase, por ejemplo, la edición de Juan Manuel Rozas (1976: 190).

10 La polémica del disfraz varonil, así como los demás aspectos polémicos del teatro, fueron reflejados por autores de la época como Francisco de Barreda (1622) o Bances Candamo (1690). Ya en nuestro siglo, estos testimonios fueron recopilados por Cotarelo (1904); y en nuestros días, por otros investigadores como Duncan Moir (1970) o Sánchez Escribano y Porqueras Mayo (1972). Recordemos que desde 1608 existen reglamentos que prohíben que las mujeres salgan a bailar o a representar en hábito de hombre y que tal prohibición se repite en 1615 y en 1641 (recogido por Varey y Shergold, 1971b: 48, 56 y 92). Algunos años más tarde, en 1644 y 1646, mueren la reina doña Isabel, primera mujer de Felipe IV, y el príncipe Baltasar. Con este motivo, señala Pellicer (1804), resucitaron las polémicas y el Consejo de Castilla formuló una orden en la que aconsejaba que se suspendieran las comedias, pero ponía como condición en caso de representarse, que las mujeres no se vistiesen de hombres y que sacasen las basquiñas hasta los pies (Edición de Díez Borque, 1975: 150 y Cotarelo, 1904: 164).

11 El cronista Gil González Dávila relata el entretenimiento palaciego que se celebró en el antiguo Alcázar de Madrid el martes de Carnestolendas, 29 de febrero de 1623. Se representó una versión burlesca de una boda de aldea en que varios miembros de la Corte aparecieron vestidos de mujer. Entre ellos, dos mayordomos del Rey, varios ayudas de cámara del Infante, un conde, etc. (documento editado por J. E. Varey, 1971a: 745-754). Casiano Pellicer (1804) recoge el festejo con que el Condeduque de Olivares obsequió a Felipe IV la noche de San Juan, conocida su inclinación «a las recreaciones y desahogos públicos», y señala la presencia de galanes disfrazados (Edición de Díez Borque, 1975: 124 y 128). 
tador, la ilusoria apariencia de realidad, dentro de la cual se introducía la ficción del teatro. Hay que tener en cuenta el ambiente teatral que impregnaba la sociedad entera del siglo XVII y su tendencia a la exageración y al espectáculo ${ }^{12}$.

Desde la perspectiva escenográfica, la función del travestismo era la de permitir la transformación del personaje en otro de sexo contrario, abandonando su crisálida ilusoria de ser real para convertirse en criatura de ficción ejecutora de una histriónica impostura. Como consecuencia de ello, en todas las obras en que se produce travestismo se observa la existencia de dos planos. Comedias y piezas cortas se caracterizan por el establecimiento de un plano de la comedia y un plano de la ficción. En el primero se presentan los elementos que conducen al personaje hacia la impostura del disfraz. Puede aparecer en cualquier momento de la obra, no necesariamente al inicio de la misma, e incluso encontrarse diseminado a lo largo de su espacio cronológico. En el segundo, el personaje se disfraza para poder lograr sus propósitos. En este plano el dramaturgo pone de manifiesto sus críticas y su ideología. Los personajes elaboran, en mayor o menor medida, un microcosmos ficticio consistente en la construcción de otro $\mathrm{u}$ otros personajes de sexo contrario.

Dentro de los autos sacramentales, como sabemos, se evidencia la existencia de dos planos diferentes: el de lo divino y el de lo humano. En el primero, se hallan las ideas o conceptos abstractos que el dramaturgo pretende transmitir. El segundo representa la plasmación de esa abstracción en una forma concreta real. Es la encarnación en un actor o actriz. La traslación de un plano al otro se realiza como adopción de una personalidad física para expresar un concepto abstracto, o sea, el concepto de idea representable se convierte en elemento fundamental de la teoría alegórica calderoniana. Avanzando un nivel más, dentro del plano de lo humano o concreto se sitúa el subplano de lo ficticio. Dentro de éste tiene lugar la ejecución de la transformación mediante el travestismo. Desde esta perspectiva, existe coincidencia entre comedias y autos, pues lo que el espectador percibe en ambos casos sobre el escenario es la presencia de actores o actrices interpretando los elementos verbales y gestuales de su discurso como personajes. En múltiples ocasiones los autos reproducen

12 Recordemos el estudio de Emilio Orozco Díaz (1969) sobre la teatralidad en aquella época, que, a pesar de contar ya con una antigüedad de tres décadas, goza de plena vigencia. 
el esquema argumental de las comedias. Incluso existen escenas en las piezas eucarísticas calcadas exactamente de aquéllas. Llámese César (Las manos blancas no ofenden) o Alma (El pleito matrimonial del cuerpo y el alma) el personaje en cuestión, lo que se ofrece sobre el tablado son dos escenas similares en las que los signos artificiales procedentes del escenario convergen en un mismo espectáculo visual. Por ejemplo, detengámonos por un momento a reflexionar sobre la escena en que aparece el Alma en brazos del Pecado en el auto mencionado:

Al acabar de bajar el alma, tropieza y cae en los brazos del Pecado (T. III, 79).

El espectáculo visual emitido desde el escenario y recibido por el espectador es similar al de una de las más atractivas escenas de la comedia Las manos blancas no ofenden, aunque en esta última el histrionismo se ve incrementado por el recurso del travestismo:

Saca Federico a Lisarda en los brazos, vestida de hombre, y Carlos a César, vestido de mujer (T. I, I, 1.094)

Y no sólo se produce la coincidencia de esta teatral escena en la comedia y el auto, sino que también la podemos hallar en la mojiganga Las visiones de la muerte en que existe convergencia de personajes e incluso mención al auto:

Saca el Cuerpo al alma en brazos (pág. 379).

Los signos verbales empleados, el código gestual y kinésico, la modalidad del disfraz, las relaciones entre los personajes, los motivos que los guían, los recursos que utilizan para engañar, sus sentimientos triunfadores o desesperados, sus emociones hacia los demás, sus pautas de comportamiento reflexivo o impetuoso, la manera de ser percibidos por otros personajes y por el propio espectador, las rupturas de la ilusión escénica, la comunicación y la complicidad con el público, la retórica..., son todos ellos elementos de convergencia entre el plano ficticio de comedias y de autos.

Pero el dramaturgo no siempre pretende el mismo grado de transformación en los personajes que utilizan el disfraz para cambiar de 
sexo. En ocasiones, ésta en realidad no se produce, sino que sirve como elemento de catarsis de las cualidades ya presentes en el personaje antes de disfrazarse. Es el caso de mujeres como Julia, de $L a$ devoción de la cruz; Semíramis, de La hija del aire; Marfisa, de Hado y divisa de Leónido y Marfisa; Matilde, de Yerros de naturaleza y aciertos de la fortuna; Ismenia, de Los tres afectos de amor; etc. En todas ellas, con respecto a la ideología conservadora de la época, tiene lugar un profundo grado de transformación al desempeñar un papel varonil definido por rasgos de carácter adjudicables únicamente a los hombres de aquella sociedad, como la valentía, la audacia e incluso la actitud temeraria. Pues bien, lo que ocurre simplemente en estas mujeres al vestirse con el traje masculino es que trasladan sus características a un ámbito, a un lenguaje y a unas formas de actuación típicamente masculinas, y entonces, como hombres, son respetados e incluso temidos. Esta metamorfosis, como veremos, se refleja en la escena dramática a través de los signos textuales y escénicos ${ }^{13}$ que lleva consigo el travestismo en la interpretación de estos personajes.

La metamorfosis que sufre Semíramis en La hija del aire se halla técnicamente perfeccionada mediante la introducción de un efecto de profundidad histriónica, pues el personaje que Semíramis ha elaborado en la ficción que lleva a cabo finge, a su vez, la exhibición de una personalidad antitética con respecto a la suya. Es decir, Semíramis finge que es Ninias - caracterizado anteriormente como ser cobarde y afeminado desde el estereotipo social femenino de la época-, que, a su vez, finge valentía para conseguir gobernar con mano firme y dura. El recurso empleado es el de la superposición de ficciones, con el que logra un efecto de magistral perspectiva dramática. Así, para hacer verosímil la impostura de Semíramis, se utilizan dos recursos: en primer lugar, desde el punto de vista de la modalidad externa, el gran parecido entre ambos, que propicia el disfraz físico; en segundo lugar, desde la perspectiva de la interpretación conductual, la ficción psíquica de unas actitudes que se suponen ausentes en el personaje que representa, pero presentes en ella anteriormente. Su personalidad varonil, que previamente había sido reprimida mediante el disfraz psicológico de sus actitudes hipócri-

13 En lo referente a la clasificación y organización de los elementos que componen ambos tipos de signos seguiremos las directrices de J. M. Díez Borque (1975: 53), por su claridad y sistematización, y las adaptaremos al análisis que requiere el recurso del travestismo. 
tas, aflora a la superficie a través de su integración en el plano de la ficción.

También existen disfraces, masculinos o femeninos, que presentan como única función la de servir para la transfiguración exterior de la fisonomía, como en el caso de Flérida, en Amor, honor y poder, y de Hércules, en Fieras afemina amor. La primera, guiada por su amor hacia Enrico y armada con un ánimo valiente y audaz, decide hacerse pasar por un hombre con el fin de ofrecerle dinero y joyas para huir a un lugar lejano donde no puedan encontrarle los hombres del rey. La facilidad de esta impostura viene dada por la circunstancia de no haber guardias en la prisión donde se halla Enrico. La transformación de Flérida despierta las suspicacias del gracioso Tosco, expresadas muy a la manera tirsiana ${ }^{14}$ :

\author{
TOSCO (Aparte) \\ iVive Cristo, que el mancebo \\ el tiple de la voz suspende \\ sin acordarse de mi!! (T. I, III, 82).
}

Y no sólo del gracioso, sino también del galán. Frente a éste, son la delicadeza y la blancura de sus manos ${ }^{15}$ los elementos que actúan como pistas del verdadero sexo de la disfrazada.

La metamorfosis de Hércules, en Fieras afemina amor, es, por un lado, impuesta - lo disfrazan mientras duerme- y, por otro, externa. Por tanto, al no existir intención por parte del disfrazado, tampoco puede darse la transformación interna del mismo, pues Hércules en ningún momento se comporta como una mujer. Sólo siente la humillación del vestido femenino, la ridiculez por su exhibición ante todo el pueblo de Libia y la traición de la mujer de quien por primera vez se había enamorado. Ni exhibe cualidades femeninas ni trata de reprimir

14 Recordemos que en muchas de las obras de Tirso de Molina las dudas surgían mayoritariamente en el gracioso, por lo cual solían adoptar un enfoque cómico ( $\mathrm{La}$ villana de la Sagra), en el galán ( $M{ }^{a}{ }^{a}$ Hernández la gallega) e, incluso, en otra disfrazada (La huerta de Juan Fernández). El tipo de terminología puesta en boca de Tosco, encaminada a expresar la juventud de la disfrazada (mancebo), fue también empleada por Tirso de Molina. En sus comedias podemos hallar denominaciones como paje, rapaza, montañesillo, muchacho, niño y mozo, en obras como Don Gil de las calzas verdes, Bellaco sois Gómez, La huerta de Juan Fernández, etc.

15 En La huerta de Juan Fernández, por ejemplo, era el pie pequeño de Petronila el elemento desencadenante de las sospechas de Tomasa; en Púsoseme el sol, salióme la luna, de Lope, los elementos sospechosos son la voz y lo lampiño; en El nacimiento de Montesinos, de Guillén de Castro, el talle; etc. 
su virilidad como en el caso de otros personajes masculinos disfrazados ${ }^{16}$, pues su identidad es perfectamente reconocible. Precisamente de su reconocimiento como hombre y como Hércules bajo la indumentaria femenina es de donde procede su ridiculización. Su transformación femenina es un castigo, una venganza y una traición por parte de una mujer a un hombre. Pasa de caracterizarse por su misoginia y espíritu combativo y guerrero a convertirse en un hombre enamorado de una mujer y capaz de abandonar las armas por ella. Éste es el elemento desencadenante de la situación planteada con el disfraz, pues, si Hércules no hubiera caído en las redes de Cupido, nunca se habría producido su acercamiento a Yole y su confianza en ella, y, por tanto, tampoco habría tenido lugar su exhibición bajo la indumentaria femenina.

En El escondido y la tapada la transformación del gracioso Mosquito en mujer al vestirse con las ropas de Beatriz, la criada, es externa y funcional, pero altamente rentable. Involuntariamente, viene a convertirse, merced a las circunstancias previas no presenciadas ni conocidas por él, en una tapada que ha llegado a la casa donde él y César se encuentran escondidos en busca de auxilio. Don Diego, padre de Lisarda y fiel prototipo del caballero barroco, intenta socorrerla, pero, debido a una confusión producida en la oscuridad nocturna, socorre a un sorprendido y agradecido Mosquito disfrazado femeninamente, creyendo que en realidad se trata de la dama que ha acudido a él huyendo de un hombre que la persigue. Así pues, la situación planteada es sólo fruto del azar, y la metamorfosis que lleva a cabo el gracioso, únicamente externa, pues Mosquito ha abandonado sus ropas masculinas y las ha sustituido por las de Beatriz. El silencio se convierte en su cómplice durante el tiempo que tiene lugar su impostura, así como en elemento fundamental para la verosimilitud de la escena, que encuentra su perfecto aliado en la oscuridad del anochecer y en la presencia de la dama tapada. Así, el posible diálogo entre ambos personajes, don Diego y Mosquito, se convierte en monólogo, ya que el gracioso sólo interviene mediante apartes destinados exclusivamente al público. Por otra parte, adopta una actitud muy distinta del de las

16 Recordemos, por ejemplo, el caso de El Aquiles de Tirso, en que el protagonista ha de reprimir una y otra vez su forma de ser masculina, sus maneras agresivas - sobre todo para con Lisandro- y su deseo amoroso para con Deidamia. Todas estas actitudes provocan la extrañeza de su contrincante, pero no evitan el ineluctable enamoramiento. S6́lo al final, cuando Aquiles queda ya fuera de todo control, se pone de manifiesto de forma patente y clara su verdadera identidad ante el asombro y la ridiculez en la que queda situado Lisandro, quien desaparece de la escena para no volver a entrar en ella. 
mujeres disfrazadas que sí sufren un profundo cambio en sus personalidades femeninas ${ }^{17}$. Este gracioso se aleja de otros graciosos del teatro barroco español que sí disfrutan de su fingida condición femenina ${ }^{18}$. Sí coincide con muchos de ellos en la comicidad que provoca su aparición en la escena, derivada en este caso tanto de la indumentaria como de la falta de correspondencia entre el receptor ficticio y el real del mensaje de don Diego, o, al menos, el que él considera real.

En este caso, el disfraz femenino no produce el efecto negativo que sobre otros hombres tiene lugar, pues Mosquito comprueba que surte el efecto deseado y que recibe ciertas atenciones externas por el hecho de parecer mujer. Pero hay que señalar que se trata de un gracioso, caracterizado dentro del teatro barroco español como un personaje cobarde e interesado, alejado por completo del típico galán que en ningún momento optaría por agradecer esas atenciones sino que se rebelaría contra ellas ${ }^{19}$.

Lo que todos los personajes disfrazados tienen en común es la construcción, mediante la elaboración y la representación de un personaje de sexo contrario al suyo, de un microcosmos, de una ficción teatral dentro de la propia obra dramática, que requiere unas pautas de interpretación verbales y gestuales determinadas, precisamente dependiendo del personaje que representan. En ocasiones, incluso, coexisten diversos planos de ficción que se entrecruzan y se superponen. Por ejemplo, en Las manos blancas no ofenden la coexistencia de varios recursos de forma simultánea como la presentación de dos personajes principales disfrazados, la múltiple personalidad de uno de ellos y el entrecruzamiento de las identidades, provocan ese magistral retorcimiento al que se halla sometida la teatralidad de la comedia. La multiplicidad derivada de la superposición de los recursos histriónicos se encuentra, a su vez, distribuida en varios planos: el de la comedia, el de la ficción dentro de la comedia y el de la

17 Recordemos personajes femeninos como Rosaura en La vida es sueño y Julia en La devoción de la cruz, cuyos disfraces funcionan como elementos catárticos de ciertas cualidades previamente presentes en ellas, pero reprimidas por considerarse masculinas.

18 Por ejemplo, Castaño en Los empeños de una casa, de Sor Juana Inés de la Cruz, quien se recrea en su arreglo y actitud femenina y consigue seducir a don Pedro. Aunque Mosquito manifiesta sentimientos positivos hacia el vestido femenino, no intenta sacarle partido más allá de su objetivo de salir de la casa. Más bien trata de pasar lo más desapercibido posible.

19 Recordemos, por ejemplo, El Aquiles de Tirso, en que el protagonista enamora sin proponérselo a Lisandro y se rebela en contra de sus distinguidas y caballerosas maneras, pues su sentido de la virilidad no le permite ser tratado como una dama. 
representación dentro de la ficción de la comedia. El espectador debe detenerse a reflexionar y a discernir acerca de quién es quién, pero no le da tiempo, pues la velocidad a que se suceden las escenas no le permite retroceder. De ahí la utilización abundante del recurso del aparte de forma intercalada a lo largo de toda la comedia para volver a situar en la univocidad del mensaje al espectador, quien trata de descifrar los signos procedentes del escenario, aunque posteriormente volverá a encontrarse inmerso en el abismo del equívoco. La culminación de la teatralidad en esta obra llega de la mano de una escena de gran perspectiva histriónica para el espectador barroco. Si tratamos de establecer la secuencia de las múltiples ficciones que se producen, nos encontramos, en primer lugar, con que César finge ser Celia y, una vez dentro de esta impostura, esta falsa Celia finge ser un galán en la representación que tiene lugar dentro de la obra. Pero no sólo se trata de una representación dentro de la comedia a la manera de la de Serafina en El vergonzoso en palacio de Tirso de Molina, cuyo disfraz hallaba su plasmación dentro del marco del plano de la ficción, sino que más bien se asemeja a la interpretación situada en el marco de la representación dentro de la ficción que tiene lugar en El Aquiles de Tirso. En ambos casos, dentro del plano ficticio del disfraz, se introduce una nueva ficción simbolizada por el papel que han de representar los disfrazados dentro de una comedia o juego. Las dos escenas comparten la perspectiva de la profundidad histriónica que otorga la creación de una ficción dentro de otra, pero con la particularidad de que la segunda ficción coincide, sin más remedio, con el auténtico sexo de los disfrazados.

La representación de César, por tanto, se convierte en un recurso teatral para la elaboración de una personalidad apócrifa con respecto a la ficción anterior y al resto de los personajes, pero real con respecto al plano de la comedia y al espectador, que conoce desde el principio, a través de los signos lingüísticos y, en especial, de los apartes, la verdadera identidad del doblemente disfrazado.

Por otra parte, los disfraces sirven, desde la perspectiva escénica, para generar una ajetreada puesta en escena y un atractivo despliegue de morbosidad e histrionismo. En ocasiones, incluso, el abandono o adopción de las indumentarias se lleva a cabo sobre el escenario, ante los ojos atónitos del espectador barroco. En La hija del aire, por ejemplo, encontramos la siguiente acotación de vestuario:

Desnúdase y queda en jubón (T. II, parte II, II, 776). 
Éste es un recurso de un gran efectismo histriónico que deleitaba al público barroco por la morbosidad que implicaba despojarse de las indumentarias propias sobre la escena ${ }^{20}$. Es como asistir en directo al abandono de la crisálida de ser real para transformarse en criatura de ficción. Es la potenciación del recurso de la profundidad dramática lograda mediante el empleo de la interpretación dentro de la representación teatral. Por otra parte, constituye una forma de complicidad entre personaje y espectador, generada por el secreto compartido, una forma de asistencia a los preliminares de lo que va a acontecer más tarde en la escena. Es la superioridad que el dramaturgo desea conceder al público sobre el resto los de personajes de la obra, un regalo al espectador tanto desde el punto de vista de la acción como desde la perspectiva histriónica, con el consiguiente movimiento escénico que lleva consigo la transformación en escena. Es la plasmación de la dicotomía univocidad-espectador / equivocidad-personajes mediante el desarrollo de tal escena sobre el tablado y a espaldas de todos los personajes a excepción de Friso, quien actúa como cómplice de ella.

En El monstruo de los jardines hallamos una acotación que también revela el abandono de la indumentaria sobre el escenario. En esta ocasión se despoja del disfraz femenino con que ocultaba su verdadera identidad:

Desnúdase y queda en traje de hombre (T. II, III, 2.020).

Si intentamos recrear y comparar ambas escenas, nos encontramos con dos actores cuya técnica ha de aplicarse de manera similar. En los dos casos tiene lugar una despedida, aunque cada uno representa una cara distinta de la misma moneda. La actriz que interpreta el papel de Semíramis se despide de su verdadera identidad, la de mujer. La emisión verbal de su discurso nos hace pensar en un momento de reencuentro con la mujer que se halla en su interior, a pesar de ser ella varonil. No podemos olvidar, evidentemente, el fuerte contenido erótico de esta escena en aquella época. El lenguaje empleado remite a la

${ }^{20} \mathrm{El}$ público barroco ya había asistido a la transformación de otros personajes en la escena, como, por ejemplo, en Bellaco sois Gómez y Habladme en entrando, de Tirso de Molina; Los empeños de una casa, de Sor Juana Inés de la Cruz; etc. Es un recurso utilizado con cierta frecuencia por los dramaturgos barrocos $\mathrm{y}$, por tanto, se supone que muy atractivo a los ojos del espectador de aquel tiempo, pues la transformación del personaje en escena implica la complicidad con el público y siempre, en todo caso, una manera eficaz de captar y retener su atención hacia el escenario. 
modestia, a los adornos femeninos y a la sensación de desnudez aun vistiendo otro atuendo. Sin embargo, esa sensación no es física sino espiritual, pues el abandono de su traje femenino representa el abandono definitivo de su verdadera identidad frente a los demás, identidad que había sido reprimida hipócritamente, y la adopción de una solemne responsabilidad. Su interpretación, por tanto, se supone reflejada en una declamación marcada por la gravedad de las circunstancias, aunque consciente de la radical decisión que ha tomado previamente. El movimiento escénico que podría suponer esta escena por el abandono de la indumentaria contrasta con la lentitud kinésica que requiere un discurso como el que ella emite. Por otra parte, el tomarse su tiempo en la interpretación de esta escena seguramente redundaría en su intensidad y en el agradecimiento del público, que así podría saborearla con más deleite. Se trata de un acercamiento de la actriz al personaje que interpreta, de un sumergirse de lleno en el mismo para lograr un impresión subjetiva que convenza al espectador y lo deje ensimismado ${ }^{21}$.

El actor que interpreta el papel de Aquiles, por su parte, también se hace eco de una despedida, aunque en esta ocasión abandona un disfraz femenino para asumir nuevamente su verdadera identidad masculina. Es el reverso de la moneda. La emisión de su mensaje verbal, contrariamente al de Semíramis, no lleva consigo connotaciones de modestia o pudor, pero sí un sentimiento de renovación no sólo física sino también espiritual. Su actitud ha de ser, por tanto, dolorida pero gozosa. Dolorida, porque el abandono de la identidad femenina implica también la despedida de Deidamia; gozosa, porque su ardor guerrero se verá satisfecho. Ambas escenas son interpretadas en solitario. Se trata, por tanto, de soliloquios directamente dirigidos al espectador, recreados en la declamación del verso y en la expresión de los sentimientos con el fin de otorgar solidez emocional a su mensaje. Todo ello, además, envuelto en el mágico histrionismo del travestismo y en la morbosidad que implicaba la visión de una cierta desnudez sobre el tablado.

En la mujer, como ya hemos señalado, la adopción del disfraz varonil implicaba un alto contenido erótico por lo ajustado de las prendas que había de vestir. En el hombre, el disfraz femenino representaba la

21 En este sentido mostramos coincidencia con Evangelina Rodríguez Cuadros (1998: 406, nota 164) en su reciente trabajo sobre la técnica del actor barroco, y compartimos su desacuerdo hacia teorías que sostienen el distanciamiento del actor con el personaje interpretado. 
transgresión por la cercanía con formas sexuales prohibidas y hasta condenadas en aquella sociedad. Aprovechando la morbosidad y atractivo que el tema suscitaba, en ocasiones los dramaturgos utilizaban mecanismos para enfocar el tema desde la dimensión cómica y carnavalesca ${ }^{22}$. Así ocurría con el famoso Cosme Pérez, alias Juan Rana, para el cual algunos dramaturgos diseñaban expresamente papeles de gracioso. También sabemos que utilizaba, entre otros recursos, el afeminamiento excesivo para provocar la risa en el público. En ocasiones, incluso, aparece disfrazado de mujer ${ }^{23}$. El propio Calderón hace uso de este personaje en algunas de sus piezas breves como los entremeses El Toreador, El desafío de Juan Rana y El triunfo de Juan Rana o la mojiganga Los sitios de recreación del rey.

Las imposturas, tanto de los personajes de las comedias y piezas breves como de los autos sacramentales, llevan consigo desde su perspectiva de recurso escénico, como ya hemos mencionado, dos tipos de signos: textuales y escénicos, que se fusionan en un conjunto orgánico y que constituyen la base fundamental en la actuación de actores y actrices.

El vestuario y las acotaciones kinésicas suelen ser coherentes con el sexo fingido del personaje disfrazado desde la perspectiva del estereotipo social. Cuando no sucede así, éste es reconocido con facilidad, bien por intereses de la acción de la propia comedia, bien porque el disfraz constituye un elemento totalmente accesorio para la misma con una función de captación de la atención y del agrado del espectador. En muchas ocasiones, a pesar de producirse un verdadero cambio mediante la ficción de la vestimenta, el personaje disfrazado despierta las sospechas de otros por la imposibilidad de ocultar ciertas cualidades ${ }^{24}$ inherentes a su sexo según los cánones de la época barroca.

22 La dimensión cómica y carnavalesca del teatro de Calderón ya fue señalada por Suárez Miramón (1995: 414), frente al tópico que frecuentemente lo encasillo en el mundo culto de la Corte y en el universo teológico de los autos sacramentales, convirtiéndolo en representante y portavoz de la cultura oficial (político-religiosa).

${ }^{23}$ Sobre Juan Rana, es preciso mencionar, por lo reciente, a Thompson (1998) y Lobato (1998). Esta última publicará próximamente un artículo aún inédito ( $\ll$ Un actor en palacio: Felipe IV escribe sobre Juan Rana»), que he podido leer gracias a su generosidad al enviármelo. Se podrá consultar en la Revista de Historia Moderna de la Universidad Complutense en un monográfico dedicado a Historia y Teatro.

24 Romera Navarro (1934: 277) hace un repaso de las principales características de las disfrazadas que delatan su verdadero sexo en obras dramáticas de diversos autores de los siglos XVI y XVII. 
Los signos textuales que acompañan al travestismo son verbalizados por el actor y poseen, entre otras funciones, la de poner en relación lenguaje y disfraz. Por ejemplo, en el auto El gran mercado del mundo, la Culpa, bajo la apariencia de mozo de mesón, se refiere a sí misma mediante el género masculino y adopta un nombre varonil: Pedro.

En el entremés $E l$ sacristán mujer, el lenguaje empleado por la disfrazada Mari López se convierte en recurso aliado e imprescindible de su transformación escénica en sacristán, pues éste aparece caracterizado en la producción entremesil como personaje que se considera poseedor de una cultura superior aunque utilice un latín macarrónico. Los signos linguiísticos procedentes de la disfrazada se convertirán, así, en el elemento axial con respecto al certamen literario en que ha de competir con un auténtico sacristán por la mano de una dama llamada Brígida. Gracias a su habilidad lingüística, Mari López logra resultar vencedora en la contienda verbal. La interpretación de la actriz se supone, por tanto, caracterizada por el desparpajo y la gracia. Además, el dramaturgo pretende que su lenguaje sea fuente de comicidad para el espectador:

\author{
MARI LÓPEZ: \\ Ese sum ego, \\ ego sum, Brígida mía, \\ ego sum, dulcis requiebrum, \\ generalis Lienciatus \\ in dancis, in zapateus, \\ in arporum que ticatum, \\ in canticis et in versus. \\ Date mihi, michi manum blanca (pág. 128, vv. 46-53).
}

Nada se indica acerca de la voz de Mari López. Podemos suponer, en primer lugar, que el tono agudo característico de su naturaleza femenina era forzado durante la ficción para lograr una inflexión grave y masculina pero reconocible como falsamente varonil. La explotación de este elemento, sin duda, conformaría una buena parte de la comicidad generada frente a los espectadores, pues ellos percibirían claramente los esfuerzos de la interpretación y la ceguera de la dama al no percibir tales signos de evidencia. Por el contrario, si imaginamos la ausencia de exageración en el tono de la disfrazada, desaparece un importante elemento de comicidad, comunicación y complicidad con el público, $y$, por tanto, se desaprovecha el uso convencional de la verosimilitud dentro del microcosmos ficticio de la comedia, pues su 
identidad femenina sería demasiado evidente para el resto de los personajes del entremés y perdería credibilidad.

En La vida es sueño Rosaura adopta tres identidades diferentes: la de un personaje masculino, la de uno femenino y la de otro caracterizado por su ambigüedad sexual. Para el reflejo de la primera, la actriz verbaliza determinados signos lingüísticos que tratan de poner en conexión su lenguaje con la adopción de una identidad masculina ficticia frente al resto de los personajes. Los mecanismos empleados son la referencia a la disfrazada en género masculino, tanto por sí misma como por otros personajes y el empleo de un vocabulario varonil en el que encuentran cabida sustantivos como «espada», precedido de un posesivo de primera persona o como «agravio» acompañado de la forma verbal pronominal «vengarme». Forma parte también de esa caracterización lingüística la expresión de la posibilidad de morir como alarde de valor masculino y del largo viaje realizado para vengarse de un agravio:

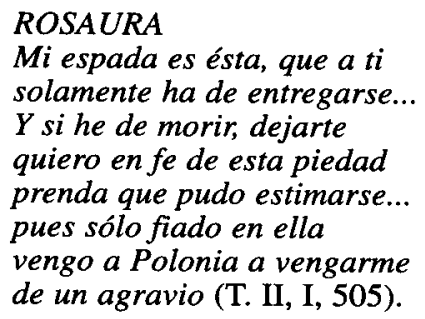

Para el reflejo de la segunda personalidad apócrifa, la femenina, Rosaura adopta un nombre femenino falso, coherente con su nueva impostura: Astrea. Además, el dramaturgo emplea un recurso utilizado también por otros autores, consistente en la simpatía que despierta la disfrazada en la dama que está siendo engañada ${ }^{25}$.

La tercera impostura de Rosaura pone de manifiesto, mediante los signos lingüísticos, la ambigüedad del personaje y la dualidad sexual existente en ella:

ROSAURA:

Mujer, vengo a persuadirte

al remedio de mi honra,

${ }^{25}$ Se emplea este recurso, por ejemplo, en La Francesilla y Más pueden celos que amor, de Lope de Vega; Atila furioso, de Virués; El cerco de Tremecén, de Guillén de Castro; Bellaco sois Gómez, La villana de la Sagra o El amor médico, de Tirso de Molina; etc. 
$y$ varón, vengo a alentarte

a que cobres tu corona.

Mujer, vengo a enternecerte

cuando a tus plantas me ponga,

$y$ varón, vengo a servirte

cuando a tus gentes socorra...

Y asi, piensa que si hoy

como mujer me enamoras,

como varón te daré

la muerte en defensa honrosa

de mi honor; porque he de ser,

en su conquista amorosa,

mujer para darte quejas,

varón para ganar honras (T. II, III, 529 y 530).

Las formas verbales empleadas en este parlamento para referirse a su actividad como mujer: persuadirte, enternecerte, darte quejas y enamorarse, y a su actividad como hombre: alentarte, servirte, ganar honras y defender su honor, representan la dicotomía lingüística y, como consecuencia, escénica, del personaje ambiguo que representa la actriz. El lenguaje mediante el cual el dramaturgo ha expresado la dualidad anímica de la disfrazada se corresponde con una estricta distinción entre la actividad femenina y la masculina de la época, según los estereotipos sociales de aquel momento. Las acciones que Rosaura se adjudica a sí misma como mujer se encuentran dentro del campo semántico del sentimiento y de la pasividad. En todas ellas se persigue la provocación de la acción en el personaje masculino. Los verbos adjudicados a sí misma como hombre pertenecen al campo de la actitud positiva y activa y son acciones valoradas dentro de aquella sociedad. Sin embargo, en ella se encuentran presentes ambos aspectos. A través del reflejo de las convenciones sociales el dramaturgo plasma en el tablado la existencia de signos escénicos marcadamente atractivos por la ambigüedad sexual que suponen. Se trata de una especie de monstruo histriónico que se compone de una doble faz femenina y masculina y capaz, por tanto, de llevar a cabo en la escena acciones y discursos propios tanto de mujeres como de hombres.

En El monstruo de los jardines, Aquiles adopta un nombre femenino acorde con su disfraz: Astrea, y es tratado por el resto de los personajes como tal. Deidamia la convierte en su amiga predilecta desde el principio. Su ficción no despierta sospechas en nadie.

El disfraz varonil de Ismenia en Los tres afectos de amor funciona como mecanismo para radicalizar su personalidad agresiva y vengativa. Los signos linguiísticos evidencian una temeridad sólo expli- 
cable desde la perspectiva de bandolero. El disfraz ha contagiado a la dama la capacidad para ejecutar un asesinato o, al menos, para intentarlo en nombre de su honor. Anteriormente, como mujer, dentro del plano de la comedia sólo había llegado a planificarlo. Más tarde, bajo el traje de bandolero, es capaz de llevarlo a cabo. La excusa dentro del nivel argumental es la negación de Anteo a cometer tal acto criminal.

Los signos lingüísticos también pueden funcionar como mecanismo para dejar al descubierto el empleo de un recurso de ficción frente al espectador. En este sentido, las tablas calderonianas presentan una clara disgregación entre el mundo real y el ficticio. El mecanismo empleado es la ruptura de la ilusión escénica a la que tan aficionado era Calderón y plasmada mediante la alusión a las convenciones teatrales o a títulos de sus propias obras de teatro. Por ejemplo, en El José de las mujeres el gracioso Capricho menciona La dama duende, y en El escondido y la tapada el gracioso Mosquito hace referencia a la comedia El privilegio de las mujeres. En El Año Santo de Roma se hace referencia al carácter alegórico y metafórico de los personajes que acompañan al Hombre en su camino hacia Roma:

\author{
LUZBEL: \\ Ellos de la frase usando \\ de alegóricos sentidos \\ y metáforas, ¿no son \\ disfrazados peregrinos? (T. III, 502).
}

La verosimilitud sigue existiendo en el teatro calderoniano como en el teatro de Lope o de Tirso, pero enfocada de manera novedosa. Ya no se trata de escenas verosímiles desde el punto de vista de la imitación -recordemos el tópico de la comedia como espejo- sino que predomina la verosimilitud como coherencia en el mundo de la fantasía. Por ejemplo, en El escondido y la tapada es bastante inverosímil la confusión de don Diego acerca de la personalidad femenina ficticia de Mosquito. Éste, a través de los apartes destinados al público, se recrea en la alusión a su ficción, pero de cara a don Diego su silencio es el elemento que concede credibilidad a su impostura dentro de la fantasía de la comedia.

Los objetivos del dramaturgo en relación con la presentación de signos textuales en uno u otro sentido se diversifican dependiendo de la 
búsqueda o no del enredo y la confusión, del nivel de equivocidad o univocidad del mensaje frente al espectador, del grado de ficción frente al resto de los personajes o de la intención cómica. Por ejemplo, en Fieras afemina amor el disfraz femenino de Hércules es reflejado, entre otros mecanismos, mediante los signos lingüísticos procedentes del gracioso Licas en clave de humor:

Si hay días en las bellezas,

hoy debe de ser su día.

pues tan hermoso despierta (T. II, III, 2.061).

En ocasiones, los signos textuales del travestismo constituyen una subversión de los discursos que se suponían masculinos y femeninos. Tanto en autos como en comedias y entremeses asistimos a declaraciones amorosas de una mujer hacia otra que está disfrazada de hombre. En El José de las mujeres, Melancia declara su amor a Eugenia cuando ésta aparece disfrazada de esclavo. En el entremés El sacristán mujer, Mari López adopta la identidad de un sacristán y doña Brígida se enamora de ella, quien la prefiere como futuro marido frente al auténtico sacristán. Incluso, a veces, el lenguaje empleado para las insinuaciones amorosas es descarado y se entra en el mundo físico de los placeres. En el auto El gran mercado del mundo la Culpa adopta el disfraz de mozo de mesón - entre otros-y el nombre de Pedro y la Lascivia se enamora de él. La escena (T. III, 232) se caracteriza por su marcado atractivo con respecto a los gustos del público barroco, pues los signos formales transmitidos desde el escenario evidencian, desde la perspectiva visual, una actriz ${ }^{26}$ disfrazada de mozo de mesón de la que se enamora la criada de la venta. Por otra parte, no nos encontramos precisamente ante un caballero y una dama que se aman y cortejan dentro de los parámetros de un código refinado, sino que asistimos a una escena en que el mozo y la criada acaban de conocerse, en la que los signos lingúísticos constituyen una transgresión de los límites impuestos en las relaciones entre hombre y mujer. Posteriormente, la misma criada que hace un momento se abrasaba de amor por Pedro, el mozo recién llegado al mesón, muestra sus encantos al Buen y al Mal Genio. La Culpa, en este último caso, actúa como Celestina de la cita amorosa. Los personajes que el espectador ve

${ }^{26}$ Suponemos que el papel de la Culpa era interpretado por una actriz, pues de esta manera es explotada toda su posible teatralidad al disfrazarse de hombre. 
sobre el tablado em-plean un lenguaje connotativo de disfrute y placer. Es decir, tras el contenido moral y religioso se evidencia una forma teatral repleta de sabrosas escenas, fuertemente impactantes para el espectador barroco y de gran atractivo por su morbosidad y descaro.

En La vida es sueño el mecanismo empleado para poner de manifiesto el recurso del disfraz es el diálogo de la protagonista con el gracioso Clarín. Aunque lo que el espectador percibe en la escena es la imagen de un hombre, Clarín se dirige a ella en género femenino. Es decir, se produce una disociación entre los signos visuales procedentes de la disfrazada y los auditivos originados en el gracioso. Sin embargo, dicha aparente inadecuación es recibida por el avezado espectador barroco como elemento unívoco del mensaje histriónico. Actúa como pista desveladora de la verdadera identidad de la disfrazada, pues el dramaturgo no basa la obra en el enredo, sino que pretende una perfecta estructuración dramática del argumento.

La función escénica del travestismo se basa fundamentalmente en la presentación de atuendos y demás signos externos y en las acotaciones kinésicas relativas a la personalidad apócrifa. Una gran parte de las indicaciones relativas al vestuario que el dramaturgo emplea para representar en las tablas el travestismo se caracteriza por el rasgo genérico y poco específico. Esto permite suponer que el atuendo utilizado se inserta en un sistema de signos visuales pertenecientes a todo un código comunicativo con el espectador barroco, que le permitía identificarlo fácilmente. De la misma manera suponemos que también era ampliamente conocido por el director de escena y los actores. Así sucede, por ejemplo, en obras como los entremeses El sacristán mujer y Las Carnestolendas. En este último se pone de manifiesto, como elemento imprescindible para otorgar sentido completo al vestuario, la colocación del actor sobre el escenario al revés y andando hacia atrás, que también indica una marcha contraria al sentido común. Así, el diseño escénico se convierte en recurso axial de la interpretación de este papel en su dimensión ilustrativa del tema del mundo al revés:

Sale un hombre, la mitad mujer, y la otra mitad de hombre, puesto al revés $y$ andando hacia atrás (p. 153).

En la mojiganga La garapiña, la acotación de vestuario pone de manifiesto no sólo un disfraz nuevamente basado en la repetición y el 
fácil reconocimiento debido a la brevedad de las indicaciones, sino también la necesidad de acompañar la presencia del actor de una apariencia andrajosa y descuidada, tal vez para dar más sensación de vejez al personaje de doña Aloja, pero también con la intención de otorgarle un cierto grado de extravagancia grotesca:

Sale Escamilla, de vieja, zarrapastroso (p. 401).

El dramaturgo ha escogido a un actor para interpretar este papel que requiere la adopción de la apariencia de una vieja. Por tanto, a la presencia en escena de un personaje fuertemente impactante por lo grotesco de su interpretación - simboliza una bebida- y por lo desaliñado de su apariencia, es preciso incrementarle la morbosidad añadida por el cambio de sexo que lleva consigo el atuendo.

En La vida es sueño encontramos las siguientes acotaciones de vestuario, que se corresponden con las tres imposturas adoptadas por la disfrazada:

Sale en lo alto de un monte Rosaura en hábito de hombre de camino, y en representando los primeros versos va bajando (T. II, I, 501).

Sale Rosaura, dama (T. II, II, 516).

Sale Rosaura, con vaquero, espada y daga (T. II, III, 528).

Con respecto a la primera acotación, es preciso destacar la divergencia existente en algunas ediciones. Augusto Cortina (1978) consideró válida la acotación que Hartzenbusch rehizo según un criterio personal con objeto de situar lo mejor posible el texto: «A un lado monte fragoso y al otro una torre cuya planta baja sirve de prisión a Segismundo. La puerta, que da frente al espectador, está entreabierta. La acción principia al anochecer». Enrique Rull (1980: 105) y, después de él, muchos otros como José María García Martín (1983), Ciriaco Morón (1985), Evangelina Rodríguez (1987) o Ruano de la Haza (1994) rechazaron tal acotación por no corresponderse con la original creación de Calderón.

Rull (1980: 105) constata también su desacuerdo con la advertencia de Hartzenbusch «tras ella viene Clarín», pues, como también supuso 
Martín de Riquer, el gracioso no interviene hasta el verso 23 y no parece seguro que haya hecho acto de presencia antes (1980: 105). La acotación de Hartzenbusch es seguida, una vez más, sin embargo, por Cortina (1978).

La segunda acotación se refiere a la adopción de la personalidad apócrifa de Astrea, la dama de Estrella.

La tercera indica la aparición de Rosaura bajo su identidad femenina pero con accesorios varoniles. Su presencia sobre el tablado como mujer ataviada masculinamente pretende reflejar escénicamente la ambigüedad sexual a la que hacíamos referencia al hablar de su lenguaje. Éste es un claro ejemplo de paralelismo total entre los signos lingüísticos y las acotaciones de vestuario.

Las acotaciones kinésicas que acompañan al recurso del travestismo presentan duplicidad de funciones, dependiendo también del doble receptor de las mismas. En primer lugar, con respecto al espectador barroco, el objetivo consiste en generar atractivo y ajetreo escénico. En el auto A María el corazón los signos kinésicos derivados de los disfraces de la Soberbia y del Peregrino se caracterizan por su morbosidad y su violencia en grado hiperbólico. La manifestación escénica de estas acotaciones en el tablado mediante los movimientos de los dos personajes disfrazados seguramente provocó el asombro y el regocijo del público asistente a la representación por lo espectacular y morboso:

\author{
Dale con un puñal y cae. \\ Sácale del pecho el corazón \\ ensangrentado. \\ Arrójale el corazón, levántase \\ ensangrentado el Peregrino y tómalo ('T. III, 1.148).
}

En segundo lugar, el dramaturgo pretende plasmar en escena la personalidad apócrifa del personaje disfrazado con el fin de conceder credibilidad a su impostura frente al resto de los personajes. Las mujeres disfrazadas varonilmente, a través de las acotaciones kinésicas, reproducen pautas de comportamiento encuadradas dentro del estereotipo de actuación masculino. Los hombres, por su parte, tratan de manifestarse corporal y actitudinalmente dentro de los parámetros de actuación femenina. El travestismo escénico, desde este punto de vista, funciona como elemento transgresor de las normas convencionales 
establecidas para cada sexo. En La devoción de la cruz las acotaciones kinésicas adjudicadas a Julia ponen de manifiesto su personalidad apócrifa de bandolero:

Salen, por otra puerta, Julia y algunos bandoleros (T. II, III, 419).

Saca la espada (T. II, III, 412).

La importancia de esta última acotación, desde nuestro punto de vista, es fundamental, pues a través de ella la conducta de Julia adquiere un rasgo de caracterización masculina. Por otra parte, la aparición de la espada imprime mayor atractivo e intensidad dramática a la escena y se potencia la actitud activa de ella frente a la pasiva de Eusebio. A pesar de ello, algunas ediciones como la de Sidney F. Wexler (1966) no la constatan.

En La hija del aire, aunque la identidad varonil que intenta suplantar Semíramis no responde al estereotipo masculino de la época - pues Ninias no es cruel, ni vengativo, ni justiciero, sino piadoso y deseoso de paz-, se comporta dentro del patrón de conducta establecido para los hombres. Aduce, claro está, que finge un valor ausente en él -como Ninias- pero desplegando en todo momento actitudes y comportamientos gestuales y kinésicos de desprecio, crueldad y espíritu combativo, como si de un estereotipo masculino de la época se tratara.

En Las manos blancas no ofenden hemos de hablar de la simultaneidad de dos grupos de signos kinésicos procedentes de los dos personajes principales que hacen uso del travestismo. En primer lugar, los relativos a la personalidad femenina fingida por César. En varias ocasiones se consigna la aparición del protagonista cantando. Se supone, por tanto, que su voz ${ }^{27}$ era de naturaleza atiplada y, por supuesto, que la tenía educada adecuadamente, pues ya desde el comienzo de la comedia él ha narrado ante los espectadores sus habilidades femeninas y entre ellas las de cantar y tocar el arpa. En cuanto a los signos kinésicos relativos a la personalidad masculina fingida por Lisarda, hay

27 Véase el interesante apunte de Becker sobre las técnicas vocales de los actores barrocos a la hora de interpretar papeles femeninos (Jean Canavaggio, 1979: 147). Véase también Evangelina Rodríguez Cuadros (1998, 446-523). 
que recordar que ésta se hace pasar por un galán dispuesto a conquistar a la princesa Serafina, para así convertirse en un obstáculo entre ésta y Federico. Así pasa a ser una firme competidora del caballero. Los movimientos y gestos de la actriz disfrazada son fundamentales para la correcta ficción del personaje varonil que interpreta. Entre ellos, el de propinar una bofetada a Federico. La respuesta de éste evidencia la credibilidad de su ficción masculina, pues saca una daga. La actitud inmediata de Lisarda ante el peligro en que se encuentra repentinamente será la de descubrirse y regresar a su verdadera identidad femenina, pues en ella se halla a salvo de esos comportamientos masculinos violentos.

En El Castillo de Lindabridis, los signos kinésicos diseñados para el personaje de la disfrazada Claridiana son plenamente reveladores de una identidad típicamente masculina de aquella época, pues se enfrenta al Fauno. La primera vez es vencida, pero en la segunda y decisiva logra la victoria. El hecho de que el Fauno caiga a los pies de Claridiana incrementa el poder histriónico de la escena, pues el espectador sabe que se trata de una dama disfrazada, y la caída a los pies de la misma se convierte en un símbolo del triunfo femenino.

También Marfisa, la disfrazada de Hado y divisa de Leónido y Marfisa, pone de manifiesto su personalidad masculina ficticia mediante una acotación kinésica de lucha. No se comporta como una mujer de aquellos tiempos sino como un hombre, pues se introduce en el campo del duelo y lucha contra Leónido, creyendo, claro está, que no es él, y motivada por la defensa del honor de éste.

En Fieras afemina amor no existen signos kinésicos para la identidad femenina ficticia del disfrazado Hércules, pues ésta se produce mientras duerme y en contra de su voluntad. Sin embargo, sí existe una acotación fundamental desde el punto de vista de la reacción de Hércules ante la transformación externa de que ha sido objeto:

Pónele el espejo (T. II, III, 2.061).

El espejo es un accesorio escénico coincidente con uno de los empleados en otra comedia mitológica y de personaje masculino disfrazado, cuya apariencia femenina es descubierta a través del mismo: El Aquiles, de Tirso de Molina. En esta comedia, el espejo constituye el elemento histriónico que viene a desvelar la identidad masculina del disfrazado ante el resto de los personajes de la comedia. Esta escena acaece cuando Ulises, conocedor del paradero del héroe y de su disfraz femenino por 
noticias de Garbón, se introduce en la corte del rey Nicomedes fingiendo ser un mercader griego que viene a ofrecerle valiosas joyas. Cuando Aquiles, aún disfrazado de Nereida, ve su reflejo en el espejo que le proporciona Ulises como parte de su rica mercancía, no puede contenerse y muestra su verdadero espíritu marcial. En el caso de Hércules, el espejo funciona como recurso para su propio descubrimiento bajo el atuendo femenino y como elemento conducente a la humillación.

Si bien Aquiles en la comedia El Aquiles de Tirso, no es capaz de controlar su ímpetu guerrero, el protagonista homónimo de El monstruo de los jardines, aunque se ve tentado por los accesorios guerreros y en un primer momento los toma, inmediatamente se percata de su error y vuelve al control y a la autodisciplina y se desprende de ellos. La acotación kinésica en que Aquiles arroja las armas es decisiva frente a las sospechas de Ulises.

En Los tres afectos de amor el dramaturgo ha empleado, para la caracterización escénica de la disfrazada Ismenia, la posesión de un arma y su utilización por causa de una venganza de honor, actitud que constituía una materia reservada de forma exclusiva al sector masculino y en la que nunca participaban las mujeres dentro de la vida real.

En consonancia con el atractivo que Calderón pretende imprimir a la escena, se observa en su dramaturgia un predominio absoluto de signos escénicos espectaculares ${ }^{28}$ en relación con el travestismo. De un total de 21 piezas en que aparece este recurso, en 11 de ellas ${ }^{29}$ se emplea un tipo de decorado ostentoso o aparatoso. Por ejemplo, en la comedia mitológica Fieras afemina amor el ambiente en que se produce la transformación de Hércules es relajado y placentero, y el decorado, grandioso y de fastuosa espectacularidad. Gracias a ello, el héroe se siente confiado y se entrega plácidamente al sueño, durante el cual

28 Según el DRAE, espectacular se define como 'aparatoso y ostentoso'. Nosotros emplearemos la expresión «marcadamente espectacular» 0 «grandioso» para referirnos a este tipo de decorado; «medianamente espectacular», para las obras en que el decorado no es grandioso, pero sí presenta apariencias, tramoyas simples, monte, jardín sencillo..., y elementos típicamente calderonianos como la gruta o la torre; «exento de espectacularidad», para aquel tipo de decorado que no ofrece ninguno de los recursos anteriores, aunque sí se utilicen brevemente otros como el baile o la música dentro del espectáculo global de la obra.

29 A María el corazón, El arca de Dios cautiva, El año santo de Roma, El castillo de Lindabridis, El gran mercado del mundo, Hado y divisa de Leónido y Marfisa, Fieras afemina amor, La protestación de la fe, Las Carnestolendas, El sacristán mujer y La garapiña. 
Yole lo adereza con accesorios femeninos. En 9 obras ${ }^{30}$--todas comedias - se utiliza un tipo de decorado medianamente espectacular. Por ejemplo, en La devoción de la cruz la metamorfosis de Julia atañe no sólo al atuendo, al lenguaje y a la actitud, sino también al lugar. El decorado utilizado como trasfondo de su transformación en bandolero es el monte. Éste aparece reflejado no mediante acotación, sino a través de signos lingüísticos:

EUSEBIO:

¿Tú, Julia, en aqueste monte? (T. II, III, 413).

La revelación de la verdadera identidad de Julia así como la confesión y arrepentimiento de sus criminales acciones se produce en un ámbito escénico de gran efectismo dramático. Son varios los significantes que se superponen en la representación de la escena para conseguir un efecto de arrobamiento en el espectador. Por una parte, el traje varonil de la disfrazada y la tramoya empleada para su ascensión a los cielos:

Vase Julia a lo alto, asida de la Cruz,

que está en el sepulcro de Eusebio (T. II, III, 419).

El lugar en que se consigna esta acotación es fundamental con respecto a la acción de la obra. Tanto dentro de la edición de Sidney F. Wexler (1966) como en la de Valbuena Briones (1991), se constata de forma inmediatamente anterior a las intervenciones de Alberto y Curcio:

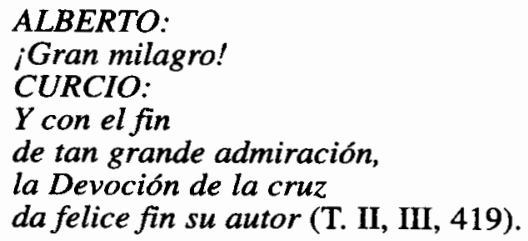

En la edición de Valbuena Prat (1930), la acotación apoteósica aparece absolutamente al final de la obra, es decir, de forma posterior a los

${ }^{30}$ La devoción de la cruz, El escondido y la tapada, la hija del aire, El José de las mujeres, Las manos blancas no ofenden, El monstruo de los jardines, Los tres afectos de amor: piedad, desmayo y valor, La vida es sueño, Yerros de naturaleza y aciertos de la fortuna. 
comentarios recién reflejados más arriba, de Alberto y Curcio. Creemos más acertada la primera opción, pues la visión de la ascensión, ya de por sí espectacular, se ve realzada así por el asombro y la admiración manifestados mediante los signos lingüísticos de ambos personajes. En el caso en que la acotación apoteósica queda relegada para el final absoluto de la obra, ésta pierde fuerza dramática, pues ya ha sido anunciado el fin del drama y la atención del espectador ha disminuido de forma considerable.

En El escondido y la tapada, el espacio escénico ha sido sabiamente configurado a través de los distintos elementos histriónicos de ocultamiento y ficción. Destaca, por encima de todos ellos, la dicotomía silencios/apartes en un escenario caracterizado por la oscuridad y compartido por el disfrazado Mosquito y la tapada Celia. Los primeros, con respecto al personaje al que se enfrenta cada uno teatralmente hablando; los segundos, con respecto al público y ambos de forma paralela, dirigidos a uno y a otro. Si tratamos de recomponer la escena, hallamos en un espacio que se supone a oscuras a dos personajes que tratan de ocultar su verdadera identidad: Mosquito, vestido de mujer, y Celia, con manto. Ambos perciben la presencia de alguien en la misma estancia donde se hallan y de la cual tratan de escapar. De cara al otro, cada uno guarda silencio absoluto y se mueve en la oscuridad intentando esquivar la presencia del otro. De cara al público, sus pensamientos son conocidos gracias a los apartes que, como sabemos, manifiestan comunicación con el espectador, pero silencio con respecto a los demás personajes. El doble juego de luz / oscuridad, apariencia / realidad, ausencia / presencia, silencios / apartes y conocimiento / ignorancia, condiciona el espacio escénico y ha de ser comunicado al espectador, por una parte, mediante movimientos lentos y silenciosos, gestos de sorpresa y de temor en sus rostros, de torpeza kinésica en la oscuridad de la estancia y de alivio al no ser descubiertos, mímica marcadamente expresiva, al fin y al cabo; por otra, mediante signos linguíísticos que pongan de manifiesto la comunicación exclusiva con el público:

CÉSAR (A la puerta):
Ya puedes
salir mejor, porque siendo
ahora cuando anochece,
antes que se enciendan luces,
podrá ser salir sin verte...

MOSQUITO:

Salga

yo ahora que es lo que conviene. 


\author{
CELIA (Aparte): \\ Un bulto se va acercando \\ $a$ mí.
}

MOSQUITO (Aparte):

Un bulto hacia mi viene.

\author{
CELIA (Aparte): \\ No podré llamar a César, \\ en tanto que no se fuere. \\ (Truecan lugares Celia y Mosquito)
}

\begin{abstract}
MOSQUITO (Aparte):
El no me ha visto, pues no

me habla nada.
\end{abstract}

CELIA (Aparte):

¡Oh si se fuese!

MOSQUITO (Aparte):

¡Oh si encontrase la puerta! (T. I, II, 695).

En sólo una comedia temprana se constata la aparición de un ambiente exento de espectacularidad: Amor, honor y poder. De las 11 obras del grupo espectacular, 5 son autos, 3 comedias cortesanas (1, además, mitológica) y 3 piezas breves. Si analizamos estos datos desde la perspectiva del género dramático, concluimos que en el $100 \%$ de los autos y piezas breves en que aparece el travestismo ( 5 de 5 y 3 de 3) aparece este recurso inserto en un ámbito de naturaleza aparatosa u ostentosa. Las comedias se encuentran mayoritariamente repartidas entre el grupo grandioso y el medianamente espectacular, pues sólo una, como hemos visto, incluye el recurso del travestismo en un ambiente exento de espectacularidad. La exégesis de estos datos se halla en relación directa con la finalidad del género. El auto persigue básicamente la transmisión de contenidos religiosos a través del asombro, la emoción y el arrobo del público. Por ejemplo, el disfraz de peregrino de la Herejía en La protestación de la fe se sitúa en un espacio de gran efectismo escenográfico en correspondencia con el momento del auto en que tanto el personaje disfrazado como el espectador asisten al clímax de la acción: la renuncia de su anterior fe por parte de la reina Cristina de Suecia y su conversión a la fe católica a través de los ritos del Sacramento Eucarístico. Los ingredientes del cóctel histriónico son: el disfraz, el decorado espectacular, la 
riqueza del vestuario y de los accesorios empleados para la caracterización de los personajes y la música.

En cuanto a las comedias, las que contienen travestismo inserto en un tipo de decorado marcadamente espectacular son las cortesanas, pues van orientadas básicamente a un tipo de público aristocrático que prefiere la grandiosidad escenográfica. El teatro breve persigue la diversión del espectador y la sátira. Por ello no precisa la suntuosidad y complejidad escenográfica de las comedias palaciegas y autos sacramentales (vestuario rico, elementos escénicos externos a los personajes como música, fuentes, jardines, animales y personajes sobrenaturales y fantásticos, apariencias y tramoyas de gran complejidad escenográfica, etc.), pero sí de otra clase de espectáculo que denominaremos aparatoso ${ }^{31}$. Se trata de un travestismo inserto en un tipo de espectacularidad coreográfica y kinésica basada, sobre todo, en la deformación de los personajes a través del vestuario ridículo, grotesco o icónico (llamativo por lo extravagante y no por lo suntuoso) y en la música y el baile presentes en la escena.

Por supuesto, no dudamos por un momento de la existencia de una determinada espectacularidad del travestismo en el teatro breve, pero en un sentido muy diferente al de autos y comedias cortesanas. Hay que tener en cuenta también el hecho de que los elementos em-pleados aparecen en la escena en un espacio muy corto de tiempo. Éste es un aspecto que se debe tomar en consideración, pues trae consigo la acumulación, recurso que conduce a la producción de espectáculo de forma indirecta. En el entremés El sacristán mujer, por ejemplo, se destaca la coexistencia del travestismo con la coreografía (el zapateado), la música y la canción. En el entremés Las Carnestolendas, el recurso del travestismo se inserta en un desfile de personajes folclóricos y carnavalescos aderezados con vestuario extravagante. Intercalado en este conglomerado estrafalario, aparece el hombre al revés, caracterizado por su condición ambigua, mitad hombre, mitad mujer. En la mojiganga La garapiña, el espectáculo procede del vestuario icónico que se halla en relación con el travestismo y la coreografía simultánea de los personajes así vestidos.

El travestismo se constituye, así, como recurso axial de la dramaturgia calderoniana. Se convierte en símbolo de su teatro y, por ello, constituye un reflejo de su propia visión dramática. Símbolo de su teatro porque

${ }^{31}$ Tomamos la segunda acepción de «aparatoso»: 'desmedido, exagerado' (DRAE). 
representa la ficción dentro de la ficción, que ya constituye de por sí la obra. Como tal, lleva consigo la complejidad que requiere la elaboración de un microcosmos en el cual se pretende insuflar vida, apariencia y actitudes creíbles al personaje ficticio elaborado a su vez por un actor o una actriz, con toda su carga textual y escénica. Y ello se produce de manera similar tanto en comedias como en piezas breves y autos sacramentales. En todo tipo de obras el travestismo funciona como elemento de atracción del espectador barroco. Era tan aplaudido por todos los públicos que ni siquiera las más severas críticas lograron extinguirlo. Y lo que gustaba del mismo era la morbosidad y el espectáculo que se desprendía de su presentación sobre el escenario. A través de la ficción que suponía el travestismo, el dramaturgo lograba acceder, y con él todo el público asistente a la representación, a un nivel que violentaba las normas establecidas. Representaba la transgresión, en primer lugar, por la utilización de signos externos referentes al sexo contrario. En la mujer implicaba un alto contenido erótico por lo ajustado de las prendas masculinas que había de vestir. En el hombre, la transgresión se hallaba en relación con formas sexuales prohibidas y condenadas. En segundo lugar, el travestismo llevaba consigo la ruptura del lenguaje y de los comportamientos estereotipados para cada sexo a través de los signos kinésicos y textuales. Mediante éstos, Calderón presenta en escena el enamoramiento de un personaje del mismo sexo, la presencia en la mujer de rasgos adjudicados tradicionalmente a los hombres o viceversa y la introducción masculina o femenina en ámbitos reservados para el sexo opuesto. El dramaturgo parte de las convenciones sociales y teatrales, pues el travestismo se inserta en un ámbito de ficción que utiliza los elementos histriónicos y escenográficos presentes en el teatro. Pero los emplea a su antojo y dentro de los que sabe que son los gustos preferidos del público barroco. Es un intercambio sencillo. Puro juego escénico, al fin y al cabo, dentro del espectáculo de la fiesta barroca y reflejo de toda una visión del teatro y de la vida por nuestro ilustre dramaturgo.

\section{RELACIÓN DE OBRAS DE CALDERÓN EN QUE APARECE EL RECURSO DEL TRAVESTISMO}

\section{Comedias}

Amor, honor y poder

El castillo de Lindabridis 
La devoción de la cruz

El escondido y la tapada

Fieras afemina amor

Hado y divisa de Leónido y Marfisa

La hija del aire

El José de las mujeres

Las manos blancas no ofenden

El monstruo de los jardines

Los tres afectos de amor: piedad, desmayo y valor

La vida es sueño

Yerros de naturaleza y aciertos de la fortuna.

\section{Autos sacramentales}

A María el corazón

El año santo de Roma

El arca de Dios cautiva

El gran mercado del mundo

La protestación de la fe.

\section{Teatro breve}

Las Carnestolendas

La Garapiña

El sacristán mujer.

\section{Referencias bibliográficas}

Bances CANDAmo, Francisco Antonio (1690). Teatro de los teatros de los pasados y presentes siglos. Edición de Duncan Moir (1970). Londres: Tamesis Books.

BARREDA, Francisco de (1622). «Invectiva a las comedias que prohibió Trajano y apología por las nuestras». En Federico Sánchez Escribano y Alberto Porqueras Mayo (eds.), Preceptiva dramática del Renacimiento y el Barroco. Madrid, 1972.

Bravo-VILlasante, Carmen (1976). La mujer vestida de hombre en el teatro español. Madrid: SGEL. 
Canavaggio, Jean (1979). «Los disfrazados de mujer en la comedia». En La mujer en el teatro y la novela del siglo XVII. Actas del Segundo Coloquio de GESTE, 135 152. Toulouse-Le Mirail: Institut d'Études Hispaniques et Hispanoaméricaines, Universidad Autónoma de Madrid.

CORTINA, Alberto (1978). La vida es sueño. Madrid: Espasa-Calpe.

COTARElo Y MORI, Emilio (1904). Bibliografía de las controversias sobre la licitud del teatro en España. Madrid: RABM.

Diccionario de Autoridades (1984). RAE. Edición facsímil de la de 1732. Madrid: Gredos.

Diccionario de la lengua española (1992). RAE. Madrid: Espasa-Calpe.

Díez Borque, José María (1975). «Aproximación semiológica a la escena del teatro del Siglo de Oro español». En Semiología del teatro, VV.AA., 5092. Barcelona: Planeta.

Garcf́a MARTín, José (1983). La vida es sueño. Madrid: Castalia.

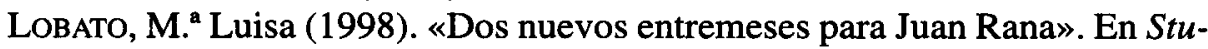
dia Hispanica. Teatro español del Siglo de Oro. Teoría y práctica, Christoph Strosetzki (ed.), 191-236. Vervuert: Iberoamericana.

- (Inédito). «Un actor en palacio: Felipe IV escribe sobre Juan Rana». Será publicado próximamente en Revista de Historia Moderna de la Universidad Complutense en un monográfico dedicado a Historia y Teatro.

Morón ArRoyo, Ciriaco (1985). La vida es sueño. Madrid: Cátedra.

Orozco DíAz, Emilio (1969). El teatro y la teatralidad del Barroco. Barcelona: Planeta.

PEllicer, Casiano (1804). Tratado histórico sobre el origen y progreso de la comedia y el histrionismo en España. Ed. de J. M. Díez Borque. Barcelona: Labor, 1975.

Rodríguez Cuadros, Evangelina y Tordera, Antonio (1982). Pedro Calderón de la Barca. Entremeses, jácaras y mojigangas. Madrid: Castalia.

Rodríguez CuAdros, E. (1987). La vida es sueño. Madrid: Espasa-Calpe. - (1998). La técnica del actor español en el Barroco. Hipótesis y documentos. Madrid: Castalia.

ROMERA NAVARRo, M. (1934). «Las disfrazadas de varón en la comedia». Hispanic Review II, 269-286.

Rozas, Juan Manuel (1976). «El arte nuevo de hacer comedias». En su obra, Significado y doctrina del Arte Nuevo de Lope de Vega. Madrid: SGEL. Ruano de la HAZA, José M. (1994). La vida es sueño. Madrid: Castalia. Rull, Enrique (1980). La vida es sueño (comedia, auto y loa). Madrid: Alhambra.

SuÁrez Miramón, Ana (1995). «Ambivalencia de la plaza pública en Calderón». En Bajtín y la literatura. Actas del IV Seminario Internacional del Instituto de Semiótica Literaria y Teatral, J. Romera, M. García-Page y F. Gutiérrez Carbajo (eds.), 411-424. Madrid: Visor Libros.

Thompson, Peter (1998). «Juan Rana, a Gay Golden Age Gracioso». En A Society on Stage. Essays on Spanish Golden Drama, Eduard H. Friedman, 
H. J. Manzari y Donald D. Miller (eds.), 239-251. Nueva Orleans: University Press of the South.

VAlBUENA BRIONES, Ángel (1987 [1960]). Calderón de la Barca. Obras completas. Tomo I: Comedias. Madrid: Aguilar.

- (1991 [1969]). Calderón de la Barca. Obras completas. Tomo II: Dramas. Madrid: Aguilar.

Valbuena Prat, Ángel (1930). Comedias religiosas. Madrid: Espasa-Calpe. «Clásicos Castellanos», vol. 106.

- (1991 [1967]). Obras completas de Calderón de la Barca. Tomo III: Autos sacramentales. Madrid: Aguilar.

VAREY, J. E. y SHERGOLD, N.D. (1971a). «La creación deliberada de la confusión: estudio de una diversión de Carnestolendas de 1623». En Homenaje a William L. Fichter, 745-754. Madrid: Castalia.

- (1971b). Fuentes para la historia del teatro en España. III, Teatros y comedias en Madrid, 1651-1665. Londres: Tamesis Books.

WeXLER, Frederick Sidney (1966). Comedia famosa de la devoción de la cruz de don P. Calderón de la Barca. Tesis de doctorado defendida en la Universidad de Nueva York. Salamanca: Anaya. 